\title{
Inhibitory Interconnections Control Burst Pattern and Emergent Network Synchrony in Reticular Thalamus
}

\author{
Vikaas S. Sohal and John R. Huguenard \\ Department of Neurology and Neurological Sciences, Stanford University Medical Center, Stanford, California 94305-5122
}

Inhibitory connections between neurons of the thalamic reticular (RE) nucleus are thought to help prevent spike-wave discharge (SWD), characteristic of generalized absence epilepsy, in thalamic and thalamocortical circuits. Indeed, oscillations in thalamic slices resemble SWD when intra-RE inhibition is blocked and are suppressed when intra-RE inhibition is enhanced. To elucidate the cellular mechanisms underlying these network changes, we recorded from RE cells during oscillations in thalamic slices and either blocked intra-RE inhibition with picrotoxin or enhanced it with clonazepam. We found that intra-RE inhibition limits the number and synchrony, but not the duration, of RE cell bursts. We then performed simulations that demonstrate how inhibition can shift network activity into a desynchronized mode simply by vetoing occasional RE cell bursts. In contrast, when intra-RE inhibition is blocked, RE cells burst synchronously, enabling even short $\mathrm{RE}$ cell bursts to promote epileptogenesis in two ways: first, by activating $\mathrm{GABA}_{\mathrm{B}}$ receptors, and second, through the $\mathrm{GABA}_{\mathrm{B}}$ receptor-independent emergence of network synchrony.

Key words: generalized absence epilepsy; spike wave discharge; thalamus; oscillations; computational modeling; $\mathrm{GABA}_{\mathrm{A}}$ receptors

\section{Introduction}

Inhibitory connections between neurons of the thalamic reticular (RE) nucleus are thought to suppress spike-wave discharge (SWD), characteristic of absence epilepsy, in thalamocortical circuits. Within the thalamus, knocking out the $\beta 3$ subunit of the $\mathrm{GABA}_{\mathrm{A}}$ receptor $\left(G A B A_{A} \mathrm{R}\right)$ selectively disrupts intra-RE inhibition, resulting in epileptiform discharges in vitro (Huntsman et al., 1999) and absence seizures in vivo (DeLorey et al., 1998). Additional evidence comes from thalamic slices, which generate spontaneous and evoked oscillations resembling sleep spindles. Blocking intra-RE inhibition with the $\mathrm{GABA}_{\mathrm{A}} \mathrm{R}$ antagonists bicuculline or picrotoxin (PTX) transforms these into SWD-like activity (von Krosigk et al., 1993; Huguenard and Prince, 1994; Jacobsen et al., 2001). Conversely, the anti-absence drug clonazepam (CZP) suppresses in vitro spindles, and this results exclusively from strengthening intra-RE inhibition (Sohal et al., 2003).

Spindles result from a cycle of events, in which RE neurons inhibit thalamocortical (TC) relay neurons, eliciting rebound bursts and resulting in re-excitation of RE neurons (von Krosigk et al., 1993). The RE nucleus (Buzsaki et al., 1988; Avanzini et al., 1993; Banerjee and Snead, 1994) and the calcium channel gene $\alpha 1 \mathrm{G}$, which is necessary for rebound bursts in TC cells (Kim et al., 2001), are both required for SWD in animal models of absence epilepsy, suggesting that similar thalamic reverberations underlie typical absence seizures. However, other forms of SWD can occur

\footnotetext{
Received June 13, 2003; revised Aug. 1, 2003; accepted Aug. 13, 2003.

This work was supported by National Institutes of Health Grants GM07365 from the National Institute of General Medical Sciences and NS34774 from the National Institute of Neurological Disorders and Stroke and the Pimley Research Fund.

Correspondence should be addressed to J. R. Huguenard at the above address. E-mail: John.Huguenard@stanford.edu.

Copyright $\odot 2003$ Society for Neuroscience $\quad 0270-6474 / 03 / 238978-11 \$ 15.00 / 0$
}

even in isolated cortex (Marcus and Watson, 1966; Steriade and Contreras, 1998).

The SWD-like oscillation observed in thalamic slices after bicuculline application requires $\mathrm{GABA}_{\mathrm{B}} \mathrm{R}$ activation and is characterized by prolonged RE cell bursts (20-60 spikes/burst) (von Krosigk et al., 1993; Bal et al., 1995b). This has led to the hypothesis that intra-RE inhibition shortens RE cell bursts, thus preventing the prolonged firing thought to drive epileptiform activity through activation of $\mathrm{GABA}_{\mathrm{B}} \mathrm{Rs}$ (Bal et al., 1995b; Golomb et al., 1996; Destexhe et al., 1996a; Destexhe, 1998).

However, this may not fully explain how intra-RE inhibition suppresses SWD. First, bicuculline blocks $\mathrm{Ca}^{2+}$-dependent $\mathrm{K}^{+}$ current as well as $\mathrm{GABA}_{\mathrm{A}}$ Rs (Debarbieux et al., 1998; Seutin and Johnson, 1999), so it is not clear whether blocking intra-RE inhibition alone prolongs RE cell bursts (see Discussion). Second, during spontaneous SWD in rats, RE cell bursts contain $<20$ spikes (Pinault et al., 2001; Slaght et al., 2002). Third, some spikewave activity is not affected by $\mathrm{GABA}_{\mathrm{B}} \mathrm{R}$ antagonists (see Discussion), and mice lacking $\mathrm{GABA}_{\mathrm{B}} \mathrm{R}$-mediated responses exhibit spontaneous SWD (Schuler et al., 2001).

To understand how, at the cellular level, blocking intra-RE inhibition elicits epileptiform activity, whereas enhancing it suppresses thalamic oscillations, we recorded intracellularly from RE cells during in vitro oscillations and applied PTX or CZP. We found that intra-RE inhibition primarily limits the number, rather than the duration, of RE cell bursts. Simulations reveal potential relevance of this effect to epileptogenesis. In the absence of intra-RE inhibition, RE cells fire short, but synchronous, bursts, and network activity resembles SWD. Intra-RE inhibition desynchronizes this activity by vetoing some RE cell bursts. These results may explain (1) how intra-RE inhibition suppresses SWD and (2) the mechanism of $\mathrm{GABA}_{\mathrm{B}} \mathrm{R}$-independent SWD. 


\section{Materials and Methods}

\section{Slice preparation}

All procedures involving animals were performed in accordance with protocols approved by the Stanford Institutional Animal Care and Use Committee, and investigators adhered to the guidelines published in the National Institutes of Health Guide for the Care and Use of Laboratory Animals. Slices were made as described in Huguenard and Prince (1994). Sprague Dawley (Simonsen Laboratories, Gilroy, CA) rat pups (11- to 13 -d-old) were deeply anesthetized with pentobarbital $(50 \mathrm{mg} / \mathrm{kg})$ and decapitated. Their brains were then rapidly removed and placed in chilled $\left(4^{\circ} \mathrm{C}\right)$ slicing solution consisting of (in $\mathrm{mM}$ ): 234 sucrose, 11 glucose, $24 \mathrm{NaHCO}_{3}, 2.5 \mathrm{KCl}, 1.25 \mathrm{NaH}_{2} \mathrm{PO}_{4}, 10 \mathrm{MgSO}_{4}$, and $0.5 \mathrm{CaCl}$, equilibrated with a $95 \% \mathrm{O}_{2}$ and $5 \% \mathrm{CO}_{2}$ mixture. We obtained $400 \mu \mathrm{m}$ horizontal slices using a vibratome (TPI, St. Louis, MO) and were incubated in $32^{\circ} \mathrm{C}$ oxygenated saline for at least $1 \mathrm{hr}$ before recording.

\section{Recording procedures}

All recordings were made in an interface chamber at $34 \pm 1{ }^{\circ} \mathrm{C}$. The superperfusion solution consisted of (in $\mathrm{mM}$ ): $126 \mathrm{NaCl}, 26 \mathrm{NaHCO}_{3}, 2.5$ $\mathrm{KCl}, 1.25 \mathrm{NaH}_{2} \mathrm{PO}_{4}, 1$ or $1.2 \mathrm{MgCl}_{2}, 2 \mathrm{CaCl}$, and 10 glucose. In some cases, the superperfusion solution included $0.1 \mathrm{~mm}$ glutamine to maintain neurotransmitter levels (Kapetanovic et al., 1993). Electrical stimuli were delivered to the internal capsule through a pair of $50-100 \mathrm{~K} \Omega$ tungsten electrodes (FHC, Bowdoinham, ME), with a separation of $\sim 100 \mu \mathrm{m}$. Extracellular multiunit recordings, which also used 50-100 $\mathrm{K} \Omega$ tungsten electrodes, were normally bandpass-filtered between 100 $\mathrm{Hz}$ and $3 \mathrm{kHz}$.

Intracellular recordings were made with sharp microelectrodes, pulled from borosilicate glass (1B100F-4; outer diameter, $1.0 \mathrm{~mm}$; inner diameter, $0.58 \mathrm{~mm}$; WPI, Sarasota, FL) using a Flaming Brown Micropipette Puller (P-80; Sutter Instruments, Novato, CA). Sharp electrodes had resistances between 80 and $120 \mathrm{M} \Omega$ when filled with $4 \mathrm{M} \mathrm{KAc}$ and $100 \mathrm{~mm}$ $\mathrm{KCl}$. Recordings were made using an AxoClamp 2A amplifier in bridge mode (Axon Instruments, Union City, CA), and voltage samples were acquired from a Digidata 1322A (Axon Instruments) at $20 \mathrm{kHz}$.

\section{Drug application}

PTX and CZP, both obtained from Sigma, were dissolved in DMSO before being added to the final solution, such that the total volume of DMSO in the superperfusion solution was $\leq 0.04 \%$. The concentrations used were as follows: bath-applied PTX: $50 \mu \mathrm{m}$, locally applied PTX: 100 $\mu \mathrm{M}$, and CZP: $100 \mathrm{~nm}$. To locally apply PTX to the RE nucleus, we used a sharp electrode with a broken tip. The micropipette used for local perfusion was placed as close as possible to and upstream from the recording electrode. Control superperfusion solution flowed through the local perfusion micropipette before and after PTX application. To limit ourselves to experiments in which drug application was truly local, we only analyzed those experiments in which the effects on RE cell activity occurred in the absence of alterations in extracellularly recorded TC cell activity (see Discussion). In some cases, local PTX application had almost immediate effects on the RE cell activity, followed, after a few minutes, by effects on the extracellularly recorded TC cell activity. In three experiments, local PTX application almost immediately altered the extracellularly recorded TC cell activity. The effects in these latter cases were indistinguishable from those of bath applied PTX, and so we included these three experiments in the analysis of bath-applied PTX.

\section{Data analysis}

To find spikes in extracellular multiunit recordings, we wrote software that detected sufficiently steep negative deflections followed by sufficiently steep positive deflections within a sufficiently short time window (Sohal et al., 2003). To compute the time difference between an intracellularly recorded RE cell spike, and the nearest burst in the simultaneous multiunit recording from TC cells, $\Delta t$, we first computed the "ratemeter," the multiunit spike rate as a function of time. Then, we multiplied the ratemeter by a Gaussian $(\sigma=75 \mathrm{msec})$ centered at the time of the RE cell spike to obtain the "weighted ratemeter." The maximum of this function is found where many TC cell spikes (a population "burst") occur close to the time of the RE cell spike. Let $t_{1}$ be the time at which the maximum of the weighted ratemeter occurs, and let $t_{2}$ be the time of the RE cell spike. Then $\Delta t=t_{1}-t_{2}$.

To detect EPSPs immediately preceding bursts in intracellular recordings, we first smoothed the membrane potential based on 2-10 adjacent analog-to-digital samples. Next, we used linear regression to compute the slope of the membrane potential at every point in time. Finally, we searched backwards, from the first spike in the burst, for points of inflection. These are defined as points at which the slope exceeds a positive threshold and the following (later) value of the slope decreases by at least $30 \%$. This point was identified as the "peak" of the EPSP. Three parameters were adjusted on a per cell basis to optimize the detection and were kept constant for a given recording: the width of the Gaussian filter used for smoothing, the number of points used for linear regression, and the slope threshold.

\section{Computational modeling}

The model is based on that of Sohal et al. (2000). Most simulations were of a network containing $100 \mathrm{RE}$ and $100 \mathrm{TC}$ cells, each of which was modeled as a single compartment. We also report results from a simulation of two coupled RE cells. All simulations were run using NEURON (Hines and Carnevale, 1997) at a temperature of $34^{\circ} \mathrm{C}$ and with a time step of $0.1 \mathrm{msec}$.

Intrinsic properties. Each TC cell had an area of $29,000 \mu \mathrm{m}^{2}$, a leak current with a conductance of $25 \mu \mathrm{S} / \mathrm{cm}^{2}$, and randomly selected reversal potential between -82 and $-79 \mathrm{mV}$, a low-threshold $\mathrm{Ca}^{2+}$ current $\left(I_{T}\right)$, $\mathrm{Na}^{+}$and $\mathrm{K}^{+}$currents underlying action potentials $\left(I_{N a}, I_{K}\right)$, a hyperpolarization-activated cationic current $\left(I_{H}\right)$, and a $\mathrm{GABA}_{\mathrm{A}}$ receptor-mediated current. The maximum conductances for voltagedependent currents were as follows: $g_{H}=0.01 \mathrm{mS} / \mathrm{cm}^{2}, g_{T}=2 \mathrm{mS} / \mathrm{cm}^{2}$, $g_{\mathrm{Na}}=50 \mathrm{mS} / \mathrm{cm}^{2}$, and $g_{K}=5 \mathrm{mS} / \mathrm{cm}^{2}$. Each RE cell had an area of 14260 $\mu \mathrm{m}^{2}$, a leak current with a reversal potential of $-77 \mathrm{mV}$, and a conductance randomly selected from a uniform distribution between 45 and 55 $\mu \mathrm{S} / \mathrm{cm}^{2}$, a low-threshold $\mathrm{Ca}^{2+}$ current $\left(I_{T s}\right), \mathrm{Na}^{+}$and $\mathrm{K}^{+}$currents underlying action potentials $\left(I_{N a}, I_{K}\right)$, a Ca ${ }^{2+}$-dependendent $\mathrm{K}^{+}$current $\left(I_{K C a}\right), a \mathrm{GABA}_{\mathrm{A}}$ receptor-mediated current, and an AMPA receptormediated current. The maximum conductances for voltage-dependent currents were as follows: $g_{T s}=3 \mathrm{mS} / \mathrm{cm}^{2}, g_{N a}=50 \mathrm{mS} / \mathrm{cm}^{2}$, and $g_{K}=5$ $\mathrm{mS} / \mathrm{cm}^{2}$. Except for $I_{K C a}$, kinetics and other details for all currents are presented elsewhere (Sohal et al., 2000). The conductance of $I_{K C a}$ was proportional to $C a_{i}$, the intracellular concentration of $\mathrm{Ca}^{2+}\left(g_{K C a}=C a_{i}\right.$ $\left.\star 1.5 \mathrm{mS} / \mathrm{cm}^{2} \mathrm{~mm}\right) . C a_{i}$ decayed via first-order kinetics, with a time constant of $24 \mathrm{msec}$ at $34^{\circ} \mathrm{C}$, toward a steady state value of $240 \mathrm{~nm}$. These kinetics reproduce the burst AHP observed in several studies of RE cells (Avanzini et al., 1989; Bal and McCormick, 1993; Contreras et al., 1993). We also verified that our simulations produced very similar results when we modeled T-type calcium currents using the constant-field equation instead of an ohmic approximation.

Network architecture. RE and TC cells were organized into two linear arrays, and all connections were local and topographic, such that each RE cell inhibited the eight nearest RE cells and the nine nearest TC cells, whereas each TC cell excited the five nearest RE cells. After a presynaptic action potential and a synaptic delay of $1 \mathrm{msec}$, synaptic conductances rose rapidly and decayed via first-order kinetics with the following time constants at $34^{\circ} \mathrm{C}: 25 \mathrm{msec}\left(\mathrm{GABA}_{\mathrm{A}} \mathrm{Rs}\right.$ in RE cells), $3.6 \mathrm{msec}\left(\mathrm{GABA}_{\mathrm{A}} \mathrm{Rs}\right.$ in TC cells), and $5.6 \mathrm{msec}$ (AMPA receptors in RE cells). Decay times of $\mathrm{GABA}_{\mathrm{A}}$ currents were based on measurements made at $24^{\circ} \mathrm{C}$ and were temperature-corrected using a $\mathrm{Q}_{10}$ of 2.2 (Huntsman et al., 1999). The reversal potential for $\mathrm{GABA}_{\mathrm{A}} \mathrm{R}$-mediated synaptic currents was $-75 \mathrm{mV}$ in RE cells and $-85 \mathrm{mV}$ in TC cells (Sanchez-Vives et al., 1997; Ulrich and Huguenard, 1997b), whereas that of AMPA receptor-mediated currents was $0 \mathrm{mV}$. Maximum synaptic conductances were $20 \mathrm{nS}$ for AMPA synapses on RE cells, $50 \mathrm{nS}$ for $\mathrm{GABA}_{\mathrm{A}}$ synapses on TC cells, and 0 or 40-100 nS for $\mathrm{GABA}_{\mathrm{A}}$ synapses on RE cells. Most simulations did not include $\mathrm{GABA}_{\mathrm{B}} \mathrm{Rs}$, but when these were present, they were also linear 


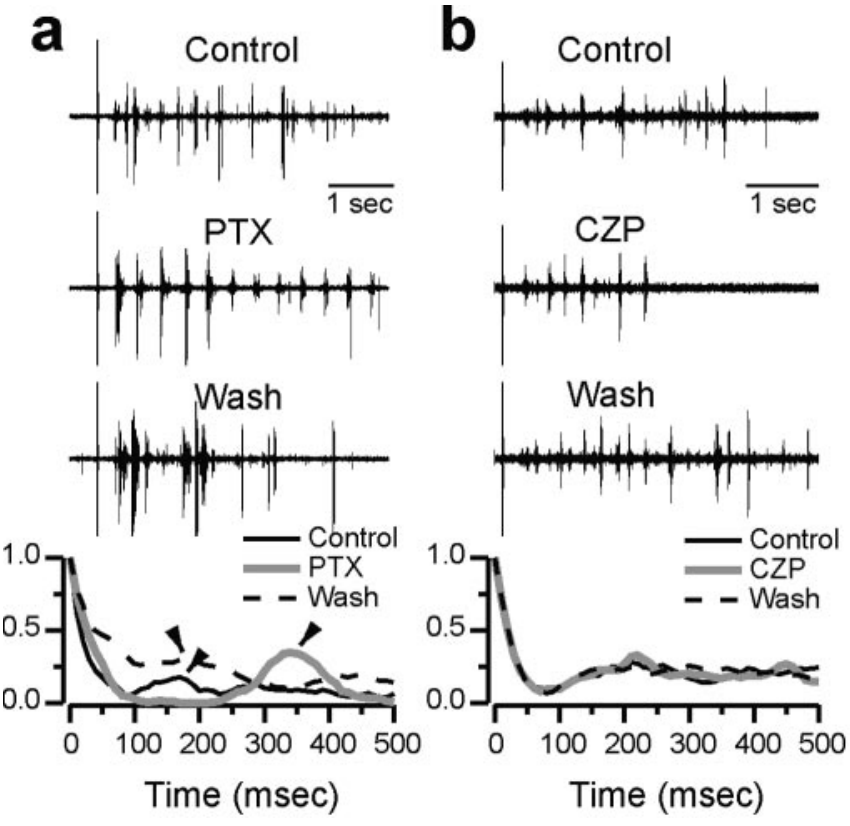

Figure 1. Effects of PTX and CZP on thalamic oscillations in vitro. $a$, Top three traces show extracellular recordings of multiunit activity from TC cells during evoked oscillations in vitro in control conditions, with PTX, and after PTX washout. The stimulus artifact is visible at the left of each trace. At the bottom, normalized autocorrelograms of the spike rate are plotted for each condition. In the autocorrelogram, the period corresponds to the location of the first nonzero peak (arrowheads), whereas the synchrony is reflected in the peak-to-trough distance. PTX reversibly slows and synchronizes oscillations. $b$, Top three traces show multiunit activity from TC cells during evoked oscillations in control conditions, CZP, and after CZP washout, and the bottom shows normalized autocorrelograms for each of these conditions. CZP shortens oscillations without affecting the period.

with first-order kinetics (rise time, $20 \mathrm{msec}$; decay time, $100 \mathrm{msec}$ at $34^{\circ} \mathrm{C}$ ) and a reversal potential of $-100 \mathrm{mV}$.

\section{Results}

\section{PTX elicits epileptiform activity in the thalamus}

As described in the Introduction, intra-RE inhibition profoundly modulates in vitro thalamic oscillations, such that SWD-like activity emerges when it is blocked, and oscillations are suppressed when it is enhanced. Figure 1 shows examples of this modulation. Figure $1 a$ shows extracellularly recorded multiunit activity from TC cells during evoked oscillations in control conditions, after bath application of $50 \mu \mathrm{M}$ PTX, and after PTX washout. Below these traces are normalized autocorrelograms of the spike rate function (ratemeter) from four consecutive evoked oscillations in each of these three conditions. Both the raw extracellular recording and the autocorrelogram show that PTX reversibly slows and synchronizes the spindle-like oscillation, producing SWDlike activity. The period of the oscillation, which corresponds to the location of the first peak away from $0 \mathrm{msec}$ in the autocorrelogram, is $\sim 150-200 \mathrm{msec}$ in control and wash, compared with $\sim 350$ msec in PTX. The synchrony of the oscillation, which corresponds to the peak-to-trough distance in the autocorrelogram, also increases dramatically in PTX. Both of these effects of PTX on oscillations in rat thalamic slices have been described in detail by Jacobsen et al. (2001) and are similar to the effects of bicuculline on oscillations in ferret thalamic slices (Bal et al., 1995a). Note that both spindle-like oscillations and slow, PTX-induced epileptiform discharges are very robust in thalamic slices taken from postnatal day 11 (P11)-P13 rats (see Discussion; Jacobsen et al., 2001).

\section{CZP suppresses thalamic oscillations}

Figure $1 b$ shows extracellularly recorded multiunit activity from TC cells during evoked oscillations in control conditions, after bath application of $100 \mathrm{~nm} \mathrm{CZP,} \mathrm{and} \mathrm{after} \mathrm{CZP} \mathrm{washout.} \mathrm{Again,}$ normalized autocorrelograms of the ratemeter from four consecutive evoked oscillations in each of these three conditions are shown below these traces. In contrast to the effects of PTX, which blocks intra-RE inhibition, CZP, which enhances intra-RE inhibition, dramatically reduces the duration of the oscillation without noticeably affecting its period. These effects are in accord with an earlier study, which found that CZP caused a reduction of $\sim 1 / 3$ in the number of spikes and a several hundred millisecond shortening in the duration of evoked oscillations in rat thalamic slices, whereas oscillation period was not affected (Sohal et al., 2003).

\section{RE cells burst more often in PTX}

To understand how modulating intra-RE inhibition with either PTX or CZP transforms thalamic oscillations, we simultaneously recorded intracellularly from an RE cell and extracellularly from multiple TC cells during spindle-like oscillations in rat thalamic slices. In a representative sample of RE cells, the resting membrane potential was $-71 \pm 3 \mathrm{mV}$, and the input resistance was $36 \pm 4 \mathrm{M} \Omega($ mean $\pm \mathrm{SE} ; n=12)$. The spindle-like oscillations, which have been characterized previously (Jacobsen et al., 2001), were evoked by a single electrical shock to the internal capsule. Figure $2 a$ shows intracellular (top) and extracellular (bottom) activity recorded during one such evoked oscillation in control conditions (left). The stimulus artifact is visible at the left of each trace. After the stimulus, the RE cell receives rhythmic clusters of EPSPs, a fraction of which elicit bursts of action potentials riding on low-threshold calcium spikes. As shown in Figure $2 a$, after bath application of PTX ( $50 \mu \mathrm{M}$, middle trace), a greater fraction of the EPSP clusters elicit RE cell bursts, and this effect reverses after PTX washout (Fig. 2a, right). For convenience we will refer to all low-threshold calcium spikes as bursts, even though many of these are crowned by just one action potential. In this cell, PTX significantly and reversibly increases the number of bursts per oscillation from $11.5 \pm 1.8$ to $23.5 \pm 1.8$ (average of four evoked oscillations; $p<0.01$ ).

In contrast to recordings from ferret slices (Bal et al., 1995b; Sanchez-Vives et al., 1997), we did not observe large, obvious IPSPs in RE neurons during evoked oscillations. This difference, although perhaps surprising, is consistent with the resting membrane potentials of our RE cells, the relatively depolarized equilibrium potential for chloride in RE cells (Ulrich and Huguenard, 1997b), and the results of simulations that will be presented later. Afterhyperpolarizations (AHPs) were commonly observed after busts, but were variable in amplitude. Because of the relatively hyperpolarized resting potential of our RE cells, the amplitudes of the AHPs were typically between 1 and $6 \mathrm{mV}$. For example, in the control trace in Figure $2 a$, there are AHPs after the first (stimulusevoked) burst, as well as the second, third, and fifth bursts, and each of these is $\sim 2-5 \mathrm{mV}$ in amplitude.

\section{PTX does not prolong bursts}

Despite its dramatic effects on the number of bursts per oscillation, PTX does not appreciably increase the number of spikes per burst in intracellular recordings from RE cells. Figure $2 b$ shows the burst evoked directly by the stimulus alongside the first burst during the subsequent oscillation for each condition: control, PTX application, and PTX washout. In this experiment, PTX had relatively little effect on the number of spikes in either the 
a

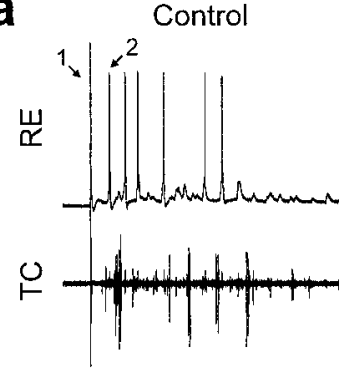

b

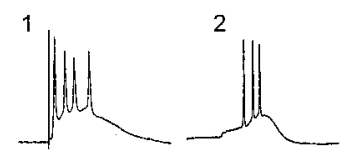

PTX
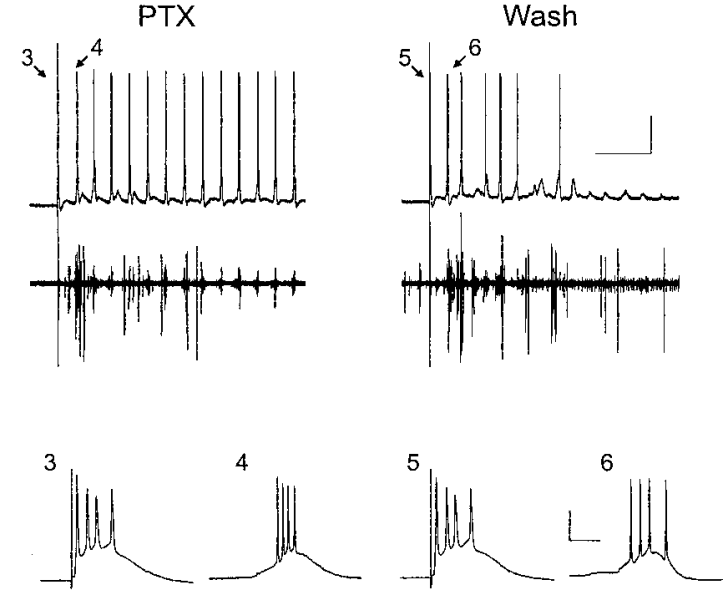

Figure 2. PTX increases the number, but not the duration, of RE cell bursts during evoked thalamic oscillations in vitro. $a$, Intracellular recording from an RE cell (top) and simultaneous extracellular recording from TC cells (bottom) during evoked oscillations in control conditions (left), during application of $50 \mu \mathrm{M}$ PTX (middle), and after PTX washout (right). The stimulus artifact is visible at the left of each trace. $b$, Bursts labeled 1, 2, etc. in $a$ are plotted here on an expanded time scale. Again, the left panel shows control traces, the middle panel shows PTX traces, and the right panel shows wash traces. Calibration: top, $1 \mathrm{sec}, 25$ $\mathrm{mV}$; bottom, $20 \mathrm{msec}, 25 \mathrm{mV}$. Resting membrane potential, $-82 \mathrm{mV}$.

a

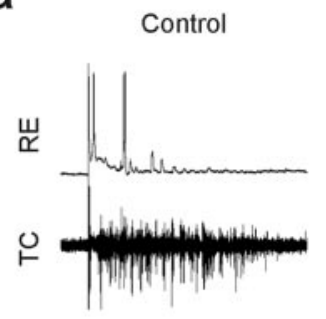

b

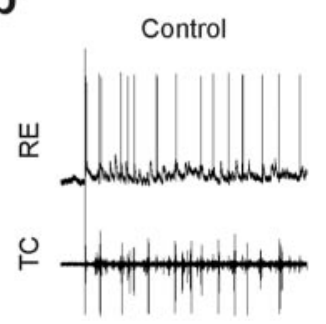

local PTX
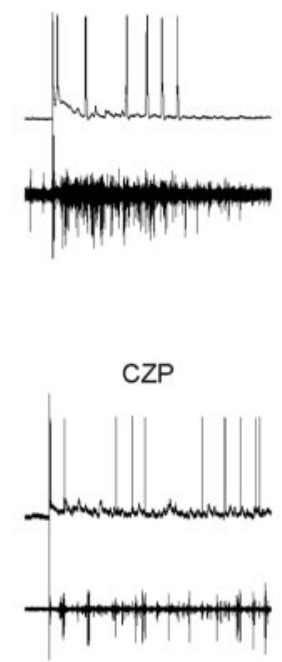

Wash
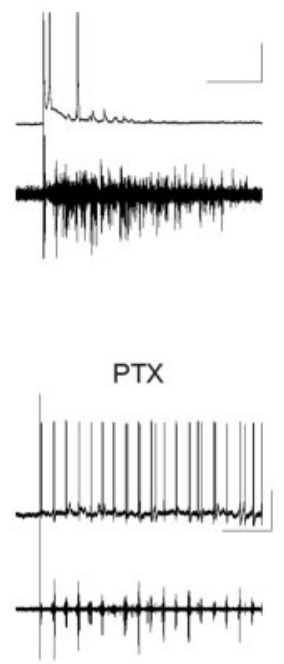

Figure 3. Effects of locally applied PTX and bath-applied CZP on thalamic oscillations in vitro. a, Intracellular recording from an RE cell (top), and simultaneous extracellular recording from TC cells (bottom) during evoked oscillations in control conditions (left), after local application of $100 \mu \mathrm{M}$ PTX to the RE nucleus (middle), and after PTX washout (right). Locally applied PTX reversibly increases the number of RE cell bursts per oscillation. Calibration: $1 \mathrm{sec}, 25 \mathrm{mV}$. Resting membrane potential, $-88 \mathrm{mV}$. $b$, Intracellular recording from an RE cell (top) and simultaneous extracellular recording from TC cells (bottom) during evoked oscillations in control conditions (left), after bath application of $100 \mathrm{~nm} \mathrm{CZP} \mathrm{(middle),} \mathrm{and} \mathrm{during} \mathrm{subsequent} \mathrm{application} \mathrm{of} 50 \mu \mathrm{m}$ PTX (right). CZP decreases the number of RE cell bursts per oscillation. The subsequent application the $G_{A B A_{A}} R$ antagonist PTX has the opposite effect. Calibration: $1 \mathrm{sec}, 25 \mathrm{mV}$. Resting membrane potential, $-62 \mathrm{mV}$.

stimulus-evoked burst or bursts during the subsequent oscillation (on average, there were $1.8 \pm 0.1$ spikes per burst in control, $2.1 \pm 0.1$ in PTX, and $1.9 \pm 0.2$ in wash). Note that these numbers are less than the number of spikes in the bursts shown in Figure $2 b$. This is the case because late in the oscillation many lowthreshold calcium spikes are crowned by just a single action potential.

PTX increased the number of bursts per oscillation in almost every cell, so that, on average, after PTX application each oscillation elicited $4.0 \pm 1.1$ additional RE cell bursts $(p<0.01 ; n=14$ cells; we analyzed a total of 250 and 297 bursts in control condi-

tions and PTX, respectively). In contrast, PTX had no consistent effect on the average number of spikes in each burst $(p=$ $0.2 ; n=8$ cells). We also quantified the effects of PTX on the RE cell bursts that immediately follow the stimulation of internal capsule (e.g., the bursts labeled 2, 4, and 6 in Fig. 2). There was no statistically significant effect of PTX on bursts evoked by weak $(<10 \mathrm{~V})$ or moderate $(10-50 \mathrm{~V})$ stimuli (data not shown). There was a significant effect ( $p<0.05 ; n=17$ cells) for bursts evoked by the strongest stimuli $(>50 \mathrm{~V})$, but even for this case, the effect is extremely modest: on average, after PTX application, these bursts contained just 0.9 additional spikes.

During extracellular recordings from the RE nucleus, we occasionally observed single-unit bursts with properties very similar to those seen in our intracellular recordings, e.g., individual RE units burst sporadically during control oscillations, these bursts contained $1-5$ spikes, and the number of spikes per burst did not change appreciably after PTX application (data not shown).

The effects of bath-applied PTX depicted in Figure 2, namely an increase in the number of RE cell bursts, may result directly from blocking $\mathrm{GABA}_{\mathrm{A}}$ receptors on RE cells, and/or indirectly from blocking $\mathrm{GABA}_{\mathrm{A}}$ receptors on TC cells and resulting changes in network activity. To distinguish these possibilities, we locally applied $100 \mu \mathrm{M}$ PTX to the RE nucleus (see Materials and Methods). Figure $3 a$ shows an example of one such experiment in which local application of PTX to the RE nucleus markedly increases bursting by this RE cell, whereas the simultaneously recorded TC cell activity was primarily unaffected by the locally applied PTX. The Fourier transform of the extracellular spike rate function over the course of this experiment confirmed this lack of effect (data not shown). Note that we only analyzed those experiments in which PTX application was judged to be focal. These were experiments in which local PTX application affected activity of the intracellularly recorded RE cell but not extracellularly recorded TC cell activity. Presumably, this dissociation occurs because the extent of the RE nucleus is much greater than the size of the perfusion micropipette, so that the locally applied PTX only blocks intra-RE inhibition in the vicinity of the recorded RE cell. Because the extracellularly recorded TC cells likely receive much of their input from RE cells that are not affected by the PTX, the overall network response recorded extracellularly is not affected by the local application of PTX. This suggests that the changes in RE cell responses observed after locally applying PTX are caused by the blockade of intra-RE inhibition, rather than global changes in the network response. 
RE cells burst an average of $2.8 \pm 0.6$ times more after local application of PTX than in control conditions $(p<0.01 ; n=7$ cells), whereas on average, each burst contains just 0.3 additional spikes ( $p<0.001 ; n=5$ cells; we analyzed a total of 133 and 192 bursts in control conditions and local PTX, respectively). There was also a small effect on the number of spikes in the burst immediately after internal capsule stimulation (data not shown). On average, the burst elicited directly by internal capsule stimulation contains one additional spike after local application of PTX $(p<0.05 ; n=7$ cells), although this reflects in large part two cells that did not burst immediately after the stimulus in control conditions, but began to do so after local application of PTX. Thus, the major effect of locally applied PTX on RE cell activity is the same as that of bath-applied PTX, namely that RE cells burst more often. Note that in this experiment, we have focused on how blocking $\mathrm{GABA}_{\mathrm{A}} \mathrm{Rs}$ in a small region of the RE nucleus affects the activity of cells within that region. This contrasts with other experiments that have studied how thalamic network activity is affected by blocking $\mathrm{GABA}_{\mathrm{A}} \mathrm{Rs}$ in the perigeniculate nucleus (PGN), the visual analog of the RE nucleus (Sanchez-Vives and McCormick, 1997). Those experiments have blocked GABA ${ }_{A}$ Rs in one location, within the PGN, and then studied the effects on $\mathrm{TC}$ cell activity recorded from a different region of the slice.

\section{RE cells burst less often in CZP}

After using PTX to block inhibition between RE cells, we studied the effects of augmenting intra-RE inhibition using CZP (100 $\mathrm{nM})$. We found that like PTX, CZP does not significantly affect the number of spikes in RE cell bursts. Whereas PTX increases the number of RE cell bursts in each evoked oscillation, CZP has the opposite effect. Figure $3 b$ shows an intracellular recording from an RE cell (top trace) and a simultaneous extracellular recording from multiple TC cells (bottom trace). After CZP application (Fig. 3b, middle), the RE cell continues to receive rhythmic EPSPs but produces fewer spike bursts. Note that after the subsequent application of PTX, not only does the CZP effect reverse, but the $\mathrm{RE}$ cell bursts more often that in control conditions (Fig. $3 b$, right). After CZP application, the number of times an RE cell burst during one oscillation decreased by $1.5 \pm 0.5(p<0.05$; $n=8$ cells), whereas the number of spikes per bursts did not change significantly ( $p=0.2 ; n=7$ cells; we analyzed a total of 238 and 192 bursts in control conditions and CZP, respectively). For the particular RE cell depicted in Figure $3 b$, many of the "bursts" consisted of just a single spike. This RE cell together with those depicted in Figures 2 and $3 a$ demonstrate the diversity of $\mathrm{RE}$ cell firing we encountered during evoked oscillations.

Figure 4 summarizes population data about the effects of bath-applied PTX, locally applied PTX, and CZP on RE cell bursting during evoked oscillations in vitro. As described above, bath and locally applied PTX both increase the number of times an RE cell bursts per oscillation, whereas CZP has the opposite effect. In every case, the number of spikes per burst remains approximately constant, changing by less than one spike. In a few cases $(n=3)$ we applied both PTX and CZP to the same RE cell. In all of these cases, PTX increased the number of bursts per oscillation, and CZP had the opposite effect. Additionally, the range of the number of bursts per control oscillation was similar for experiments in which we applied either PTX or CZP (0.015.6 and $1.0-16.5$, respectively).

\section{Intra-RE inhibition modulates RE cell excitability}

Presumably, RE cells burst more often in PTX, and less often in CZP because intra-RE inhibition reduces RE cell excitability by
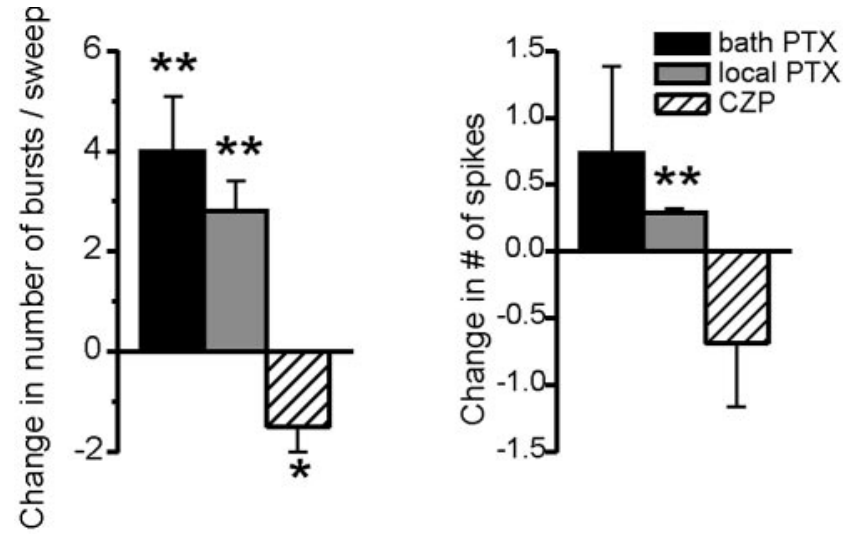

Figure 4. Intra-RE inhibition controls the number of RE cell bursts, but not their duration. $a$, Average change in the number of RE cell bursts per oscillation after bath application of $50 \mu \mathrm{m}$ PTX (black bar), local application of $100 \mu \mathrm{M}$ PTX to the RE nucleus (gray bar), or bath application of $100 \mathrm{~nm}$ CZP (hatched bar). Blocking intra-RE inhibition significantly increases the number of bursts, whereas CZP, which augments intra-RE inhibition, significantly decreases the number of bursts $\left({ }^{*} p<0.05 ;{ }^{* *} p<0.01\right)$. b, Average change in the number of spikes per RE cell burst during evoked oscillations in the same three conditions. Pharmacological manipulations of intra-RE inhibition alter the number of spikes per burst by less than one spike, and only in one case are these changes statistically significant. (Number of cells per condition varies between 5 and 14; see Results for details.)

shunting EPSCs and/or the low-threshold T-type $\mathrm{Ca}^{2+}$ currents that underlie RE cell bursts. One prediction of this hypothesis is that measures of RE cell excitability such as EPSC-burst coupling should be enhanced by PTX and suppressed by CZP. To test this prediction we determined the probability that EPSPs of a given amplitude elicited bursts in control conditions, CZP, and PTX. First we selected experiments with large numbers of EPSPs and bursts per evoked oscillation, and minimal variability in the resting membrane potential. Within each experiment, we detected the EPSP immediately preceding each burst, as described in Materials and Methods. We also detected EPSPs that failed to elicit bursts. Using the maximum voltage attained by these two classes of EPSPs, we then calculated the burst probability as a function of EPSP amplitude in different conditions. For every condition, we included all of the EPSPs and bursts after a single shock to internal capsule (these intracellularly recorded events usually continued for several seconds).

Figure $5 a$ shows the EPSPs detected by our algorithm on four consecutive RE cell bursts during one evoked oscillation. Figure $5 b$ shows the burst probability as a function of EPSP amplitude for this same RE cell, in control conditions, CZP, and PTX. Large EPSPs ( $>10 \mathrm{mV}$ in amplitude) almost always evoke bursts in all three conditions. However, only a fraction of moderate-sized EPSPs $(<10 \mathrm{mV})$ evoke bursts, and the probability that such an EPSP results in a burst is highest in PTX and lowest in CZP. Figure $5 b$ shows population data for the effects of PTX and CZP on the probability that moderate-sized $(0-10 \mathrm{mV})$ EPSPs elicit bursts. PTX significantly increases by burst probability by $0.50 \pm$ 0.20 ( $n=3$ cells), whereas the burst probability significantly decreases in CZP, by $0.097 \pm 0.003$ ( $n=3$ cells). For every experiment, we found that the distribution of EPSPs that did or did not elicit bursts were significantly different in control conditions and after drug application ( $p<0.05, \chi^{2}$ test; PTX, $n=3$ cells; CZP, $n=3$ cells). This confirms that the changes in the number of RE cell bursts observed in PTX and CZP are not caused by indirect network effects, but rather by modulation of RE cell excitability, presumably mediated by intra-RE inhibition. 
a

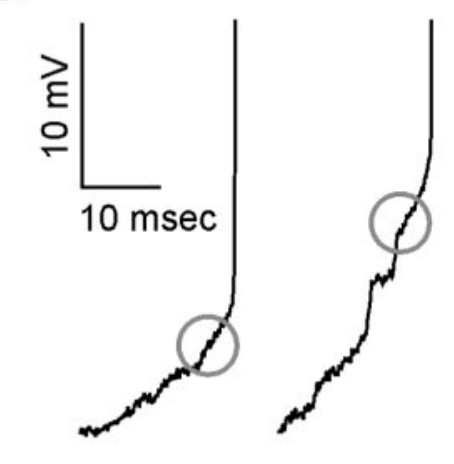

b

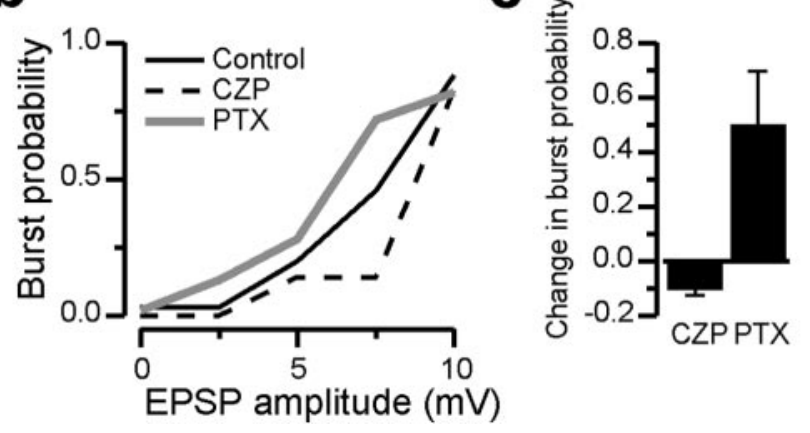

Figure 5. Intra-RE inhibition controls RE cell responsiveness. $a$, Examples of the last EPSPS detected immediately preceding each RE cell burst. Only the final few EPSPs preceding each burst are shown. Traces are shown for each of four consecutive bursts during an evoked oscillation. A circle is superimposed on each trace, centered on the peak of the detected EPSP. The resting membrane potential of this $R E$ cell was $-82 \mathrm{mV}$, and for this cell the spike threshold, i.e., the point at which the membrane potential begins to rise very steeply, was always between -59 and $-56 \mathrm{mV}$. $b$, The probability that EPSPs of a given amplitude elicited bursts in the RE cell depicted in $a$, in control conditions (solid black line), PTX (gray line), and CZP (dotted black line). At each membrane potential between 2 and $8 \mathrm{mV}$, bursts were most frequently elicited in PTX and least often in CZP. c, The average change in the probability that EPSPs $<10 \mathrm{mV}$ in amplitude successfully elicit bursts after application of CZP ( $n=3$ experiments) or PTX ( $n=3$ experiments).

\section{CZP desynchronizes RE cell bursts}

Intra-RE inhibition may influence the timing as well as the number of bursts in RE cells during thalamic oscillations. To explore this possibility, we computed the timing difference between intracellularly recorded RE cell spikes and extracellularly recorded TC cell activity (see Materials and Methods) in control conditions and after CZP application. We could have also studied how timing differences were affected by bath-applied or locally applied PTX, but there were practical reasons why we didn't do this. First, bath-applied PTX dramatically alters the period of evoked oscillations (Fig. 1a) (Jacobsen et al., 2001), making it difficult to compare timing differences during control oscillations to those during PTX oscillations. Second, as described above, locally applied PTX only affects a small region of the RE nucleus. As a result, local application does not disrupt the overall network response, so the relative timing of activity in all locations of the slice may not be affected. For these two reasons, we focused on how timing differences were affected by CZP application.

Figure $6 a$ shows the times of intracellularly recorded RE cell spikes (vertical bars) superimposed on the extracellular ratemeter (black line) for one oscillation in control conditions (left) and after CZP application (right). Figure $6 b$ shows the timing difference between each of these RE cell spikes and the ratemeters, and the panels in $b$ are plotted on the same horizontal time scale.

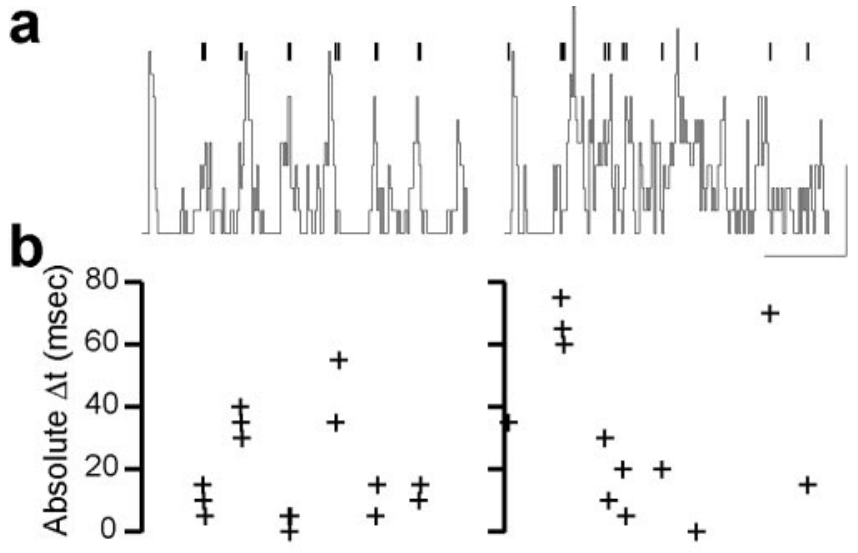

Figure 6. CZP desynchronizes RE cell bursts during evoked oscillations in vitro. $a$, Times of intracellularly recorded RE cell spikes (bars) superimposed on the TC cell extracellular spike rate (ratemeter, line) for one oscillation in control conditions (left) and after CZP application (right). Calibration: $500 \mathrm{msec}, 400$ spikes/sec. $b$, Absolute timing difference between each of these RE cell spikes and the nearest burst in the TC cell ratemeter (see Materials and Methods). $a$ and $b$ are plotted on the same horizontal time scale, so each cross in $b$ represents the phase of the intracellular spike located directly above it in $a$.

Thus, each cross in $b$ represents the relative timing of the intracellular spike located directly above it in $a$. Qualitatively, the relationship between the times of intracellular spikes and the extracellular ratemeter appears more regular in control conditions than after CZP application. Quantitatively, the timing differences are distributed close to zero in control, but scatter more widely in CZP. The trends observed for this particular cell hold true in a population of RE cells. The mean absolute timing difference increases from $24.9 \pm 1.4 \mathrm{msec}$ in control conditions to $30.8 \pm 1.2$ msec after CZP application ( $p<0.01 ; n=6$ cells). This suggests that intra-RE inhibition regulates not only the number, but also the relative timing, of RE cell bursts during thalamic oscillations.

\section{Intra-RE inhibition desynchronizes model RE cells}

The preceding experimental observations suggest that intra-RE inhibition can control the number and timing of RE cell bursts during thalamic oscillations. We used simulations to confirm that first, intra-RE inhibition can produce these effects at the level of RE cells, and second, that these effects are sufficient to explain the occurrence of epileptiform activity when intra-RE inhibition is blocked and the suppression of oscillations when intra-RE inhibition is augmented. Before simulating a complete RE-TC network, we studied the role of intra-RE inhibition in a simulation of two RE cells. Figure 7 shows the responses of these model RE cells to identical, $10 \mathrm{~Hz}$ trains of EPSCs. Each compound EPSC in this train consisted of four unitary EPSCs at a frequency of $200 \mathrm{~Hz}$. The two RE cells are identical except in their leak conductances (which differ by $\sim 20 \%$ ). In the absence of inhibitory interconnections (red traces, left), the two cells burst synchronously on every cycle of the excitatory train. In contrast, when they are connected by inhibitory synapses with conductances of $50 \mathrm{nS}$, then the two cells almost immediately settle into a pattern of anti-synchronous subharmonic bursting. The mechanism by which intra-RE inhibition controls the pattern of RE cell responses in this case is simple and evident. Heterogeneity in the intrinsic properties of the two RE cells result in one beginning to burst before the other. Inhibition from the earlier bursting RE cell "vetoes" bursting in the other RE cell, i.e., the latter cell fails to burst on that cycle of excitatory input (one such vetoed burst is indicated by an asterisk in Fig. 7). The "vetoed" cell (which failed 
No intra-RE inhibition Intra-RE inhibition present
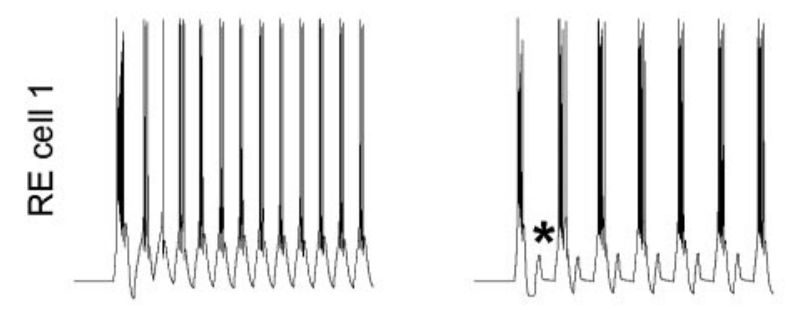

$25 \mathrm{nS}$
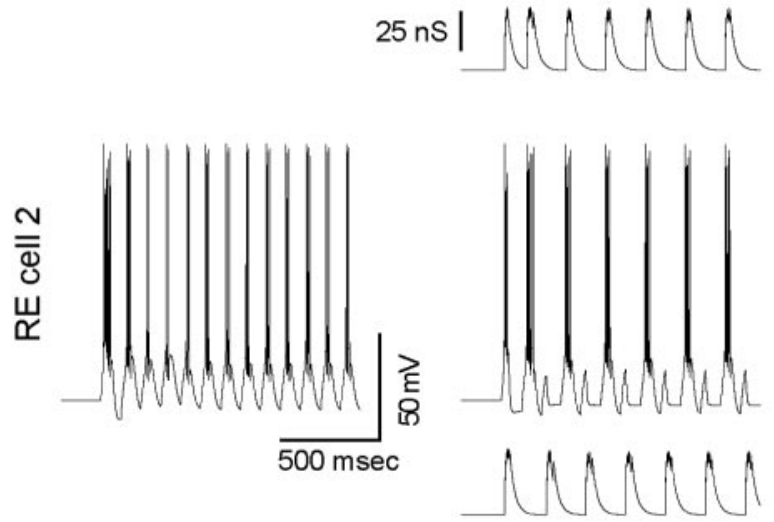

Figure 7. Intra-RE inhibition desynchronizes model RE cells. The responses of two model RE cells to identical, $10 \mathrm{~Hz}$ trains of EPSCS, are shown when intra-RE inhibition is absent (left) and when the two cells connected by inhibitory synapses with conductances of $100 \mathrm{nS}$ (right). The two RE cells are identical except for their leak conductances, so that the resting membrane potentials of the cells depicted in the top and bottom traces, respectively, are -76 and -73 $\mathrm{mV}$. For the case that includes intra-RE inhibition (right), the $\mathrm{GABA}_{\mathrm{A}} \mathrm{R}$ conductance is plotted below the voltage trace for each RE cell. When intra-RE inhibition is present, it desynchronizes bursting in the two RE cells, by vetoing $\left(^{*}\right)$ excitatory input on alternate cycles.

to burst) then has more deinactivated T-current (and less residual $I_{K C a}$ ) when the next cycle of excitation arrives, and as a result, it bursts rapidly. Now the RE cell which did burst on the previous cycle is inhibited and fails to burst. In this way, intra-RE inhibition forces the two RE cells to burst on alternate cycles of the excitatory train. This ability of intra-RE inhibition to veto RE cell bursts can be appreciated fully by comparing the $\mathrm{GABA}_{\mathrm{A}} \mathrm{R}$ conductance on each RE cell, which is plotted below the membrane potential of that cell, to the timing of bursts in that cell.

Note the profound influence of inhibition on the behavior of these cells occurs in the absence of visible IPSPs, similar to what we observed in vitro. This accords with the relatively depolarized equilibrium potential for chloride in RE cells (Ulrich and Huguenard, 1997b). Note also the AHP after bursts. This AHP results from $I_{K C a}$, which terminates bursts in our model RE cells. Similar AHPs are evident in most of our intracellular recordings from RE cells (Figs. 2, 3).

\section{Intra-RE inhibition desynchronizes simulated network oscillations}

Having shown that inhibition can control the pattern of bursts in a pair of interconnected RE cells, we studied whether intra-RE inhibition could also influence the burst pattern during network oscillations and how its influence might control the emergent network activity. As described in Materials and Methods, we simulated oscillations in a network containing 100 RE cells and 100 TC cells. As before, the RE cells differ only in their leak conductances. Figure $8 a$ shows $2.5 \mathrm{sec}$ of activity in one network with intra-RE inhibition (left; $\mathrm{GABA}_{\mathrm{A}}$ conductance on each RE cell, 40 $\mathrm{nS}$ ), and in another without intra-RE inhibition (right). Note that the networks depicted in Figure $8 a$ lack $\mathrm{GABA}_{\mathrm{B}}$ Rs on TC cells. In each case, the top two panels show the times at which RE and TC cells at different locations in the network spike. Each of the top panels depicts the activity of all the cells in the network. The $y$-axis corresponds to the location of the cell in the network, and the $x$-axis represents time, so that a horizontal row of spikes represents the spike train of a single neuron. In Figure $8 a$, the bottom panels show the summed spike activity of TC cells throughout the network as a function of time, i.e., the total number of TC cell spikes occurring during each 10 msec bin. In both networks, we instantaneously set the initial voltage of two-thirds of the RE cells to $-40 \mathrm{mV}$, so that they produced bursts and together initiated network activity. After this initial stimulus, both networks exhibited oscillatory activity in which individual neurons burst repetitively.

Almost immediately after the initiating stimulus, the patterns of activity in the two networks diverge. In the network with intra-RE inhibition, RE and TC cells burst somewhat sporadically, interburst intervals are irregular, and the times of bursts are desynchronized across the network. In contrast, in the network without intra-RE inhibition, RE and TC cells burst at regular intervals, and the times of bursts are tightly synchronized across the network. As a result, when intra-RE inhibition is present, the summed TC cell activity reveals low-amplitude, irregular oscillations suggestive of spindles, whereas in the absence of intra-RE inhibition, the summed TC cell activity exhibits very regular, high-amplitude oscillations resembling epileptiform discharges.

Note that in Figure $8 a$, when intra-RE inhibition is removed, the amplitude and synchrony of oscillations both increase markedly, but unlike the results of PTX application in vitro, the period of oscillations does not become noticeably slower. This is because the simulations depicted in Figure $8 a$ lack $\mathrm{GABA}_{\mathrm{B}}$ Rs. This was done to simulate the relatively high frequencies of rodent SWD and of in vitro epileptiform activity in $\beta 3$ knock-out mice. In addition, the occurrence of epileptiform activity in networks devoid of $\mathrm{GABA}_{\mathrm{B}}$ Rs demonstrates a novel mechanism for SWD that does not require $\mathrm{GABA}_{\mathrm{B}} \mathrm{Rs}$. The latter are necessary to simulate slower $(\approx 3 \mathrm{~Hz})$ oscillations observed in human SWD and after application of PTX or bicuculline in vitro (Golomb et al., 1996; Destexhe et al., 1996a; Destexhe, 1998). When postsynaptic $\mathrm{GABA}_{\mathrm{B}} \mathrm{Rs}$ are included in model TC cells (see Materials and Methods; the $\mathrm{GABA}_{\mathrm{A}}$ and $\mathrm{GABA}_{\mathrm{B}}$ conductances on each TC cell were 40 and $20 \mathrm{nS}$, respectively) and intra-RE inhibition is blocked (Fig. $8 b$, right), the oscillations not only become more synchronized and larger in amplitude, but much slower $(\approx 3-4$ $\mathrm{Hz}$ ) as well, reproducing the effects of $\mathrm{GABA}_{\mathrm{A}} \mathrm{R}$ blockade that have been observed both in thalamic slices from ferret and rat (Bal et al., 1995a; Jacobsen et al., 2001) and in previous models (Golomb et al., 1996; Destexhe et al., 1996a). Whereas these previous models featured large changes in the duration of RE cell bursts, in our model, changes the pattern of RE cell bursts, without dramatic prolongation of these bursts, are sufficient to activate $G_{A B A}$ Rs and slow thalamic oscillations.

Figure $9 a$ shows the membrane potential for a pair of RE and TC cells located at the center of the network with (left, black traces) or without (right, red traces) intra-RE inhibition. The behavior of these individual neurons correlates well with the different levels of synchrony in the two networks. When intra-RE inhibition is absent, the RE cell bursts on every cycle of the network oscillation. As a result, the TC neuron receives strong inhibitory input at regular intervals, and this elicits many robust rebound bursts. In contrast, when intra-RE inhibition is present, $\mathrm{RE}$ cell bursting is sporadic and irregular. As a result, in this 
a

Intra-RE inhibition present
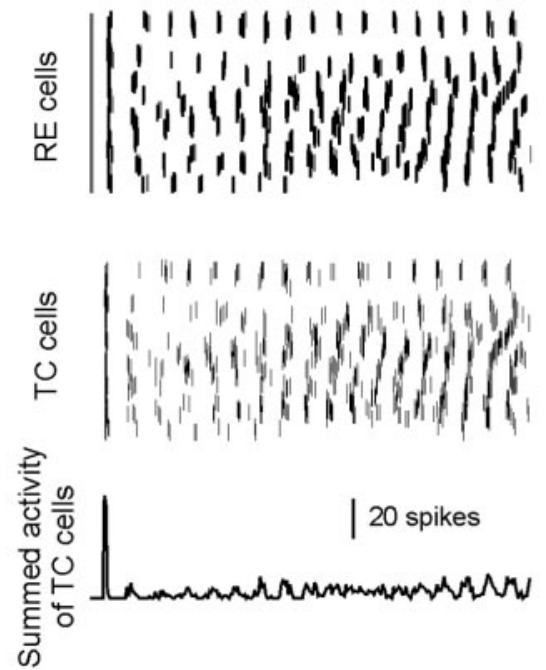

b

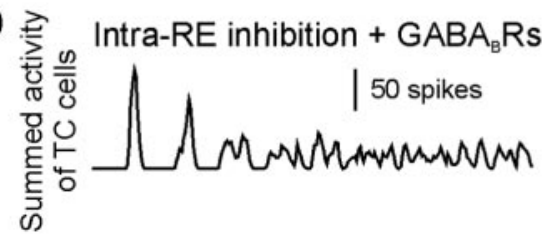

No intra-RE inhibition
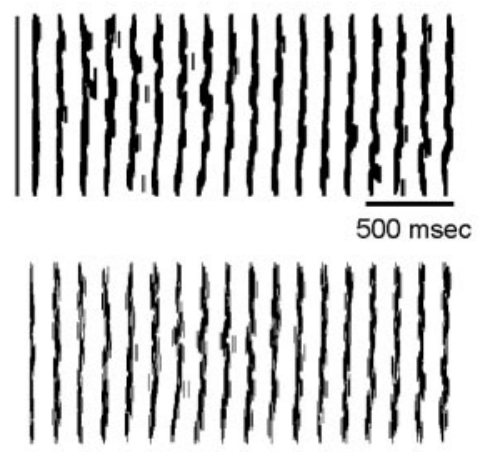

Iduldubulduldur

$\mathrm{GABA}_{\mathrm{B}} \mathrm{Rs}$ w/o intra-RE inhibition

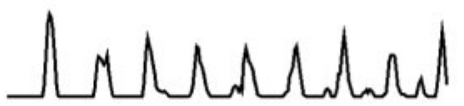

Figure 8. Intra-RE inhibition desynchronizes oscillations in a simulated thalamic network. a, Activity in a network with intra-RE inhibition (left; $\mathrm{GABA}_{\mathrm{A}}$ conductance on each RE cell, $50 \mathrm{nS}$ ) and a network without intra-RE inhibition (right). The top panels show the times at which RE and TC cells at different locations in the networks spike, and the bottom panels shows the summed activity of TC cells throughout each network as a function of time. Activity was initiated in both networks by instantaneously depolarizing two-thirds of the RE cells above their threshold for bursting. b, Summed TC cell activity in networks with postsynaptic GABA ${ }_{B} R s$ on TC cells (the GABA and $G A B A_{B}$ conductances on each TC cell are 40 and $20 \mathrm{nS}$, respectively). As in $a$, desynchronized spindle-like oscillations occur when intra-RE inhibition is present (left, $\mathrm{GABA}_{\mathrm{A}}$ conductance on each RE cell $=100 \mathrm{nS}$ ). In contrast to $a$, the epileptiform discharges that occur in the absence of intra-RE inhibition (right, 3.7 Hz) are much slower than the spindle-like oscillations (left, $9.1 \mathrm{~Hz}$ ).

network the TC cell rebound bursts less often than it did in the absence of intra-RE inhibition, and these rebound bursts often contain just one or two spikes.

Two mechanisms make bursting sporadic for this RE cell in the network with intra-RE inhibition. First, after the initial stimulus, when the first cycle of recurrent excitatory input arrives in this RE cell, the level of intra-RE inhibition is very high, so that this cell fails to burst. Several nearby RE cells also fail to burst, so that nearby TC cells receive insufficient inhibitory input to rebound burst. Thus, part of the network, including this RE cell, is silent for a few cycles. This phenomenon can be seen best in Figure 8 (left). Note the absence of several cycles of spikes in groups of adjacent RE or TC cells. Second, even after this RE cell begins receiving enough rhythmic excitatory input to burst, it does so sporadically, because the crests of rhythmic intra-RE inhibition are often strong enough and timed appropriately to shunt excitatory input and prevent this RE cell from bursting. This is illustrated by Figure $9 b 1$, which shows the membrane potential (top trace) and excitatory (black line) and inhibitory (thick gray line) synaptic conductances (lower traces) for the RE cell in the network with intra-RE inhibition, during the period of time labeled $b 1$ in Figure $9 a$. Note that when the peak of synaptic inhibition occurs just after the peak of synaptic excitation, the burst is vetoed. Through these two mechanisms, intra-RE inhibition can silence a small part of the network for several cycles, or prevent an individual RE cell from bursting on individual cycles of a thalamic oscillation. In contrast, the RE cell in the network without intra-RE inhibition receives robust excitatory input, which is unchallenged by inhibition, and reliably elicits bursts (Fig. 9b2).

Figure $9 c$ shows typical bursts from the RE cell in the network with intra-RE inhibition (left; average number of spikes per burst $=3.9$, based on analysis of 237 bursts from 100 model cells) and from the RE cell in the network without intra-RE inhibition (right; average number of spikes per burst $=5.3$ based on analysis of 547 bursts from 100 model cells). As in intracellular recordings from RE cells, blocking intra-RE inhibition prolongs RE cell bursts only slightly.

\section{Discussion}

Blocking inhibitory synapses between RE cells produces epileptiform activity in the thalamus, whereas augmenting these same synapses suppresses thalamic oscillations. Here, we examined how, at the level of RE cells, these changes in network oscillations occur. Recording intracellularly from RE cells during evoked spindle-like oscillations in thalamic slices, we found that after blocking intra-RE inhibition with PTX, RE cells burst more often. Conversely, strengthening intra-RE inhibition with CZP reduces the number of times per oscillation that each RE cell bursts. Through all of these manipulations, the number of spikes per burst remained approximately constant, changing by at most one spike. These changes in the number of bursts induced by PTX or CZP reflected altered propensities for RE cells to burst in response to EPSPs. During evoked oscillations, strengthening intra-RE inhibition also increased timing differences between RE cell spikes and network activity. Thus, intra-RE inhibition controls the number and timing of RE cell bursts during thalamic oscillations.

In simulations we found that, as in vitro, intra-RE inhibition shunted EPSCs in RE cells, reducing the number of times RE cell burst in response to excitatory input, and thereby controlling the type of emergent activity in model thalamic networks. When intra-RE inhibition was absent, RE cells burst synchronously, providing robust inhibitory input that elicited regular, synchronous rebound bursts from TC cells. This resulted in epileptiform discharge. In contrast, when intra-RE inhibition was present, the first RE cells to burst in response to excitatory input inhibited the rest and prevented them from bursting. Thus, RE cell bursting was desynchronized, and consequently, TC cells burst sporadically and at varying times across the network, generating spindlelike oscillations.

\section{Effect of intra-RE inhibition on RE cell bursts}

As shown by Figure 5, intra-RE inhibition reduces the ability of EPSPs to elicit bursts. Because T-current is concentrated in the dendrites of RE cells (Destexhe et al., 1996b), this may reflect the 


\section{a Intra-RE inhibition present No intra-RE inhibition}
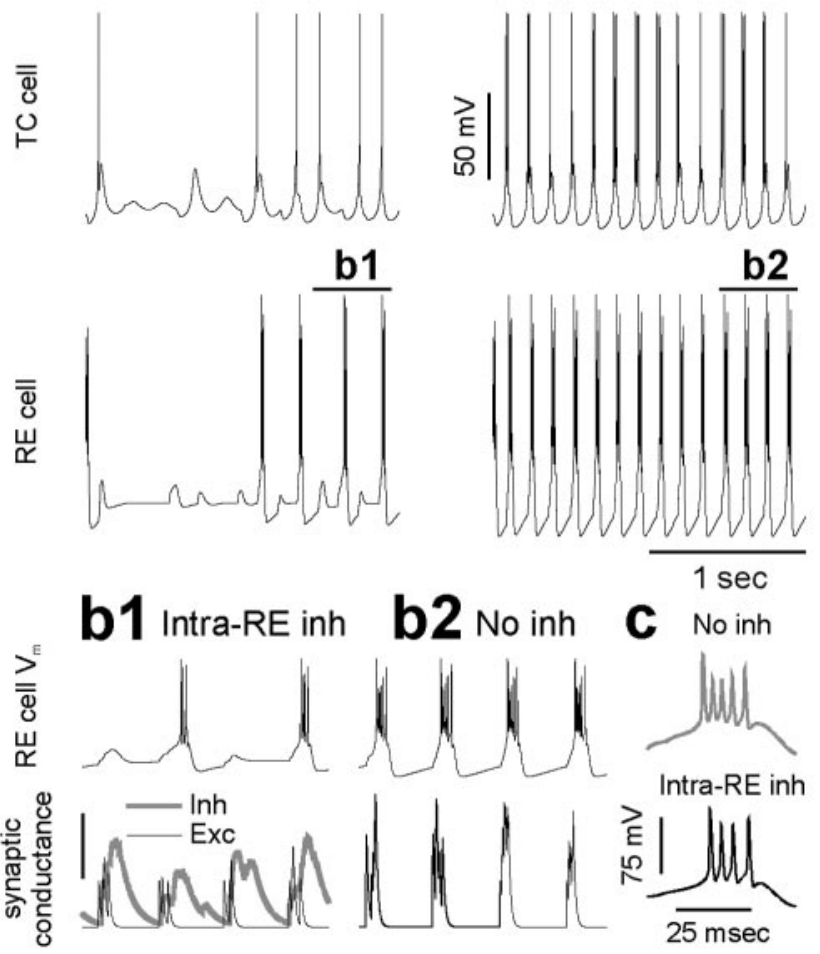

Figure 9. Intra-RE inhibition reduces the number of RE cell bursts during oscillations in simulated thalamic networks. $a$, Membrane potentials for a pair of RE and TC cells located at the center of the network with (left) or without (right) intra-RE inhibition. The resting membrane potentials of the RE and TC cells are -75 and $-66 \mathrm{mV}$, respectively. b1, The membrane potential (top trace), and excitatory (black line) and inhibitory (thick gray line) synaptic conductances (bottom traces) are plotted for the RE cell depicted in a for the period of time labeled b1. The peak of synaptic inhibition occurs shortly after the peak of synaptic excitation, preventing a burst in some cases. The scale bar represents $8 \mathrm{nS}$ of inhibitory conductance or $5 \mathrm{nS}$ of excitatory conductance. 62 , The membrane potential (top trace) and excitatory synaptic conductance (bottom trace) are plotted for the RE cell depicted in $a$ for the period of time labeled $b 2$. This RE cell is in the network without intra-RE inhibition. As a result, strong excitation, unopposed by inhibition, reliably elicits bursts. c, Typical bursts from the RE cell when intra-RE inhibition is present (left, black trace; average number of spikes per burst, 3.9) and when intra-RE inhibition is absent (right, gray trace; average number of spikes per burst, 5.3).

ability of $\mathrm{GABA}_{\mathrm{A}} \mathrm{R}$-mediated currents in RE cell dendrites to prevent the propagation of $\mathrm{T}$-current activation, in much that same way that dendritic inhibition can prevent the backpropagation of action potentials (Tsubokawa and Ross, 1996).

The ability of IPSPs to veto bursts in the RE nucleus or its visual analog, the PGN, has been noted previously (SanchezVives et al., 1997; Ulrich and Huguenard, 1997a). However, studies in ferret PGN (von Krosigk et al., 1993; Bal et al., 1995b) have identified prolonged PGN bursts as essential components of epileptiform discharges and emphasized that the main function of intra-PGN inhibition is to prevent such prolonged bursts. In contrast, our results suggest that intra-RE inhibition controls the number, not the duration, of RE cell bursts. Various factors may explain this difference. First, much of the work in ferret PGN used bicuculline to block intra-PGN inhibition. However, in addition to blocking $\mathrm{GABA}_{\mathrm{A}} \mathrm{Rs}$, bicuculline also blocks a $\mathrm{Ca}^{2+}$. dependent $\mathrm{K}^{+}$current, $I_{K C a}$, in RE cells (Debarbieux et al., 1998). Thus, the burst prolongation observed after bicuculline application may result, at least in part, from the suppression of $I_{\mathrm{KCa}}$, which is known to terminate RE cell bursts (Debarbieux et al., 1998). Another study did find that more specific $G_{A B A_{A}} R$ antag- onists, e.g., penicillin, could prolong PGN responses to glutamate application, but these responses are much more prolonged than synaptically driven bursts (Sanchez-Vives et al., 1997).

A second factor that may contribute to the differences between our observations and those made in ferret PGN is that our experiments were done in slices from juvenile rats, whereas the others were done in adult ferrets. The fact that our experiments were done in young rats does not diminish their relevance, because both spindle-like oscillations and PTX-induced epileptiform discharges are particularly robust in slices made from rats at this age (Fig. 1) (Jacobsen et al., 2001). And although it is possible that the absence of prolonged bursting after PTX application in our preparation reflects relatively low levels of T-current in young RE cells, two observations argue against this interpretation. First, even when we did observe RE cells bursts containing 5-10 spikes, these were not appreciably prolonged by PTX or shortened by CZP. Second, if the levels of T-current are low in this preparation, then it may actually be easier for intra-RE inhibition to shunt T-current and shorten bursts. As RE cells mature and the level of T-current increases, intra-RE inhibition may have even less of an effect on burst duration. Only if the strength of intra-RE inhibition increased relative to T-current, could intra-RE inhibition affect burst duration in more mature RE cells. Finally, the function of intra-RE inhibition we have proposed, reducing the number of RE cell bursts, is not mutually exclusive with a role in controlling burst duration.

\section{Intra- $R E$ inhibition, $R E$ cell bursts, and $\mathrm{GABA}_{\mathrm{B}} \mathrm{R}$ dynamics}

Paired recordings have demonstrated that $G_{A B A} R$ activation in postsynaptic TC cells of the LGN requires prolonged bursts $(>30$ spikes) in individual presynaptic PGN neurons (Kim et al., 1997). Here, we recorded robust thalamic oscillations in bath-applied PTX. These oscillations depend on $\mathrm{GABA}_{\mathrm{B}} \mathrm{R}$ activation (Jacobsen et al., 2001), yet during these oscillations, we never observed prolonged $R E$ cell bursts, suggesting that $G_{A B A} R$ activation does not require prolonged presynaptic discharge in individual $\mathrm{RE}$ cells. The $\mathrm{GABA}_{\mathrm{B}} \mathrm{R}$ activation that occurs during thalamic oscillations in the presence of PTX may reflect cooperative activation of receptors by GABA released from multiple RE cells (Destexhe and Sejnowski, 1995), because RE cells burst more often after PTX application. Alternatively, the functional threshold for $\mathrm{GABA}_{\mathrm{B}} \mathrm{R}$ activation may be lower in rat than in ferret, consistent with the observations that $\mathrm{GABA}_{\mathrm{B}}$ Rs contribute to normal spindles in rat slices (Jacobsen et al., 2001) but not in ferret slices (von Krosigk et al., 1993).

\section{Intra-RE inhibition controls network oscillations}

Our experiments and simulations suggest two new aspects of the control of thalamic oscillations by intra-RE inhibition. First, we find that intra-RE inhibition functions mainly to control the number, rather than the duration, of RE cell bursts. When intra-RE inhibition is blocked, RE cells burst more often, and these bursts, although short, can activate $\mathrm{GABA}_{\mathrm{B}} \mathrm{Rs}$ and induce epileptiform discharges. Second, in simulations, we found a novel mechanism, aside from $\mathrm{GABA}_{\mathrm{B}} \mathrm{R}$ activation, through which blocking intra-RE inhibition may contribute to epileptiform activity. When intra-RE inhibition is present, it desynchronizes RE cell activity by vetoing occasional bursts, but when it is absent, RE cells burst synchronously, allowing thalamic networks to settle into globally synchronized oscillations. Whereas $\mathrm{GABA}_{\mathrm{B}} \mathrm{R}$ activation is a cellular-level nonlinearity that mediates switching between spindle-like and epileptiform modes of activity, the synchronization of RE cell bursting engages nonlinearities 
on the network-level, e.g., synchronized RE cells robustly inhibit TC cells, eliciting synchronized rebound bursts which then further synchronize RE cells, etc. This $\mathrm{GABA}_{\mathrm{B}} \mathrm{R}$-independent mechanism may contribute to epileptiform activity in vitro and spikewave discharges in vivo in conjunction with increased $G_{A B} A_{B} R$ activation. It might also be responsible for certain $G_{A B A} R$ independent forms of spike-wave discharge. For example, knockout of the $\beta_{3}$ subunit of the GABA $\mathrm{R}$, which selectively disrupts intra-RE inhibition and produces epileptiform discharges in vitro (Huntsman et al., 1999), also results in SWD during spontaneous absence-like seizures in vivo, and these are resistant to the $\mathrm{GABA}_{\mathrm{B}} \mathrm{R}$ antagonist CGP 35348 (DeLorey et al., 1998). In addition, knock-out mice without $\mathrm{GABA}_{\mathrm{B}(1)}$ lack all $\mathrm{GABA}_{\mathrm{B}} \mathrm{R}$ mediated responses, but occasionally exhibit SWD during spontaneous atypical absence type seizures (Schuler et al., 2001). Finally, during spontaneous spike-wave discharge in WAG/Rij rats, microiontophoretic application of another $\mathrm{GABA}_{\mathrm{B}} \mathrm{R}$ antagonist, CGP 55845A, does not affect TC cell firing (Staak and Pape, 2001).

We have described a mechanism in which, by vetoing bursts, intra-RE inhibition desynchronizes RE cell activity. It is also possible that desynchronized network activity further reduces the number of RE cell bursts. In hippocampal pyramidal cells, outof-phase activity can itself "veto" subsequent bursts (Harris et al., 2001).

A mechanism in which increased numbers and synchronization of RE cell bursts drives epileptiform activity is consistent with recent intracellular and single-unit recordings from RE neurons during spontaneous spike-wave discharges in the Generalized Absence Epilepsy Rat from Strasbourg (GAERS). RE cells burst irregularly during background oscillations, but once SWD begins, RE neurons burst on every cycle, in synchrony with simultaneously recorded TC neurons (Pinault et al., 2001). Likewise, pairs of simultaneously recorded RE cells fire asynchronously during background activity, but burst within a few milliseconds of each other during SWD (Slaght et al., 2002). Both of these studies found relatively modest increases in burst duration during transitions from background activity to SWD, e.g., from a mean of 5.6 to 8.5 spikes per burst (Slaght et al., 2002) or from $2-13$ to $8-13$ spikes per burst (Pinault et al., 2001). Neither study observed the markedly prolonged bursts, containing 20-60 spikes, seen in ferret slices after bicuculline application (Bal et al., 1995b). One difference between our simulations and SWD in vivo, is that model TC cells fire low-threshold $\mathrm{Ca}^{2+}$ spikes containing 2-3 spikes, whereas during SWD in vivo, TC cells only fire single spikes or, rarely, short bursts (Pinault et al., 1998). This may reflect the lack of corticothalamic feedback in the model.

The proposal that inhibitory synapses between RE cells reduce the number and synchrony of RE cell bursts differs not only from the idea that intra-RE inhibition mainly controls burst duration and downstream $\mathrm{GABA}_{\mathrm{B}} \mathrm{R}$ activation, but also from hypotheses that intra-RE inhibition paces and sustains thalamic oscillations by eliciting rebound bursts in RE cells (Steriade et al., 1987) or that it spreads activity by depolarizing RE cells (Bazhenov et al., 1999). This proposed function also differs from the role of interconnections between inhibitory neurons in the hippocampus, which are thought to synchronize gamma oscillations (Whittington et al., 1998). The effects of intra-RE inhibition we have described may explain how absence epilepsy can result when intra-RE inhibition is attenuated, and suggest that interventions that either strengthen intra-RE inhibition, retard burst initiation in RE cells, or otherwise desynchronize RE cell bursts may be effective in preventing absence seizures. Indeed, both the anatomic location of RE cells, and the molecular composition of their $\mathrm{GABA}_{\mathrm{A}} \mathrm{Rs}$ are relatively unique. Thus, although absence epilepsy and SWD may arise from a variety of thalamocortical lesions, RE cells and intra-RE inhibition may constitute particularly efficient therapeutic targets. Finally, the effects of intra-RE inhibition also illustrate how by occasionally "vetoing" firing, inhibitory synapses can shift emergent network activity into a desynchronized state.

\section{References}

Avanzini G, de Curtis M, Panzica F, Spreafico R (1989) Intrinsic properties of nucleus reticularis thalami neurones of the rat studied in vitro. J Physiol (Lond) 416:111-122.

Avanzini G, Vergnes M, Spreafico R, Marescaux C (1993) Calciumdependent regulation of genetically determined spike and waves by the reticular thalamic nucleus of rats. Epilepsia 34:1-7.

Bal T, McCormick DA (1993) Mechanisms of oscillatory activity in guineapig nucleus reticularis thalami in vitro: a mammalian pacemaker. J Physiol (Lond) 468:669-691.

Bal T, von Krosigk M, McCormick DA (1995a) Synaptic and membrane mechanisms underlying synchronized oscillations in the ferret lateral geniculate nucleus in vitro. J Physiol (Lond) 483:641-663.

Bal T, von Krosigk M, McCormick DA (1995b) Role of the ferret perigeniculate nucleus in the generation of synchronized oscillations in vitro. J Physiol (Lond) 483:665-685.

Banerjee PK, Snead OC (1994) Thalamic mediodorsal and intralaminar nuclear lesions disrupt the generation of experimentally induced generalized absence-like seizures in rats. Epilepsy Res 17:193-205.

Bazhenov M, Timofeev I, Steriade M, Sejnowski TJ (1999) Self-sustained rhythmic activity in the thalamic reticular nucleus mediated by depolarizing $\mathrm{GABA}_{\mathrm{A}}$ receptor potentials. Nat Neurosci 2:168-174.

Buzsaki G, Bickford RG, Ponomareff G, Thal LJ, Mandel R, Gage FH (1988) Nucleus basalis and thalamic control of neocortical activity in the freely moving rat. J Neurosci 8:4007-4026.

Contreras D, Dossi Có, Steriade M (1993) Electrophysiological properties of cat reticular thalamic neurones in vivo. J Physiol (Lond) 470:273-294.

Debarbieux F, Brunton J, Charpak S (1998) Effect of bicuculline on thalamic activity: a direct blockade of $\mathrm{I}_{\mathrm{AHP}}$ in reticularis neurons. J Neurophysiol 79:2911-2918.

DeLorey TM, Handforth A, Anagnostaras SG, Homanics GE, Minassian BA, Asatourian A, Fanselow MS, Delgado-Escueta A, Ellison GD, Olsen RW (1998) Mice lacking the $\beta_{3}$ subunit of the $\mathrm{GABA}_{\mathrm{A}}$ receptor have the epilepsy phenotype and many of the behavioral characteristics of Angelman syndrome. J Neurosci 18:8505-8514.

Destexhe A (1998) Spike-and-wave oscillations based on the properties of $\mathrm{GABA}_{\mathrm{B}}$ receptors. J Neurosci 18:9099-9111.

Destexhe A, Sejnowski TJ (1995) G protein activation kinetics and spillover of gamma-aminobutyric acid may account for differences between inhibitory responses in the hippocampus and thalamus. Proc Natl Acad Sci USA 92:9515-9519.

Destexhe A, Bal T, McCormick DA, Sejnowski TJ (1996a) Ionic mechanisms underlying synchronized oscillations and propagating waves in a model of ferret thalamic slices. J Neurophysiol 76:2049-2070.

Destexhe A, Contreras D, Steriade M, Sejnowski TJ, Huguenard JR (1996b) In vivo, in vitro and computational analysis of dendritic calcium currents in thalamic reticular neurons. J Neurosci 16:169-185.

Golomb D, Wang XJ, Rinzel J (1996) Propagation of spindle waves in a thalamic slice model. J Neurophysiol 75:750-769.

Harris KD, Hirase H, Leinekugel X, Henze DA, Buzsaki G (2001) Temporal interaction between single spikes and complex spike bursts in hippocampal pyramidal cells. Neuron 32:141-149.

Hines ML, Carnevale NT (1997) The NEURON stimulation environment. Neural Comp 9:1179-1209.

Huguenard JR, Prince DA (1994) Clonazepam suppresses GABABmediated inhibition in thalamic relay neurons through effects in nucleus reticularis. J Neurophysiol 71:2576-2581.

Huntsman MM, Porcello DM, Homanics GE, DeLorey TM, Huguenard JR (1999) Reciprocal inhibitory connections and network synchrony in the mammalian thalamus. Science 283:541-543.

Jacobsen RB, Ulrich D, Huguenard JR (2001) GABA(B) and NMDA recep- 
tors contribute to spindle-like oscillations in rat thalamus in vitro. J Neurophysiol 86:1365-1375.

Kapetanovic IM, Yonekawa WD, Kupferberg HJ (1993) Time-related loss of glutamine from hippocampal slices and concomitant changes in neurotransmitter amino acids. J Neurochem 61:865-872.

Kim D, Song I, Keum S, Lee T, Jeong MJ, Kim SS, McEnery MW, Shin HS (2001) Lack of the burst firing of thalamocortical relay neurons and resistance to absence seizures in mice lacking alpha $(1 \mathrm{G}) \mathrm{T}$-type $\mathrm{Ca}(2+)$ channels. Neuron 31:35-45.

Kim U, Sanchez-Vives MV, McCormick DA (1997) Functional dynamics of GABAergic inhibition in the thalamus. Science 278:130-134.

Marcus EM, Watson CW (1966) Studies of the bilateral cortical callosal preparation. Trans Am Neurol Assoc 91:291-293.

Pinault D, Leresche N, Charpier S, Deniau JM, Marescaux C, Vergnes M, Crunelli V (1998) Intracellular recordings in thalamic neurones during spontaneous spike and wave discharges in rats with absence epilepsy. J Physiol (Lond) 509:449-456.

Pinault D, Vergnes M, Marescaux C (2001) Medium-voltage 5-9-Hz oscillations give rise to spike-and-wave discharges in a genetic model of absence epilepsy: in vivo dual extracellular recording of thalamic relay and reticular neurons. Neuroscience 105:181-201.

Sanchez-Vives MV, McCormick DA (1997) Functional properties of perigeniculate inhibition of dorsal lateral geniculate nucleus thalamocortical neurons in vitro. J Neurosci 17:8880-8893.

Sanchez-Vives MV, Bal T, McCormick DA (1997) Inhibitory interactions between perigeniculate GABAergic neurons. J Neurosci 17:8894-8908.

Schuler V, Luscher C, Blanchet C, Klix N, Sansig G, Klebs K, Schmutz M, Heid J, Gentry C, Urban L, Fox A, Spooren W, Jaton AL, Vigouret J, Pozza M, Kelly PH, Mosbacher J, Froestl W, Kaslin E, Korn R, Bischoff S, Kaupmann K, van der PH, Bettler B (2001) Epilepsy, hyperalgesia, impaired memory, and loss of pre- and postsynaptic $\mathrm{GABA}(\mathrm{B})$ responses in mice lacking $\mathrm{GABA}(\mathrm{B}(1))$. Neuron 31:47-58.
Seutin V, Johnson SW (1999) Recent advances in the pharmacology of quaternary salts of bicuculline. Trends Pharmacol Sci 20:268-270.

Slaght SJ, Leresche N, Deniau JM, Crunelli V, Charpier S (2002) Activity of thalamic reticular neurons during spontaneous genetically determined spike and wave discharges. J Neurosci 22:2323-2334.

Sohal VS, Huntsman MM, Huguenard JR (2000) Reciprocal inhibitory connections regulate the spatiotemporal properties of intrathalamic oscillations. J Neurosci 20:1735-1745.

Sohal VS, Rudolph U, Keist R, Huguenard JR (2003) Dynamic GABA A receptor subtype-specific modulation of the synchrony and duration of thalamic oscillations. J Neurosci 23:3649-3657.

Staak R, Pape HC (2001) Contribution of GABA(A) and GABA(B) receptors to thalamic neuronal activity during spontaneous absence seizures in rats. J Neurosci 21:1378-1384.

Steriade M, Contreras D (1998) Spike-wave complexes and fast components of cortically generated seizures. I. Role of neocortex and thalamus. J Neurophysiol 80:1439-1455.

Steriade M, Domich L, Oakson G, Deschênes M (1987) The deafferented reticular thalamic nucleus generates spindle rhythmicity. J Neurophysiol 57:260-273.

Tsubokawa H, Ross WN (1996) IPSPs modulate spike backpropagation and associated $[\mathrm{Ca} 2+] \mathrm{i}$ changes in the dendrites of hippocampal CA1 pyramidal neurons. J Neurophysiol 76:2896-2906.

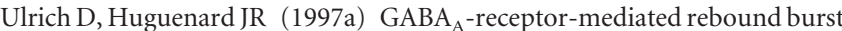
firing and burst shunting in thalamus. J Neurophysiol 78:1748-1751.

Ulrich D, Huguenard JR (1997b) Nucleus-specific chloride homeostasis in rat thalamus. J Neurosci 17:2348-2354.

von Krosigk M, Bal T, McCormick DA (1993) Cellular mechanisms of a synchronized oscillation in the thalamus. Science 261:361-364.

Whittington MA, Traub RD, Faulkner HJ, Jefferys JG, Chettiar K (1998) Morphine disrupts long-range synchrony of gamma oscillations in hippocampal slices. Proc Natl Acad Sci USA 95:5807-5811. 